\title{
The impact of the quality of materials on the differentiation of the reliability of a reinforced concrete beam
}

\author{
Izabela Skrzypczak ${ }^{1, *}$, Lidia Buda-Ożóg ${ }^{1}$, Joanna Kujda ${ }^{1}$ \\ ${ }^{1}$ Rzeszow University of Technology, Poznańska 2. 35-084 Rzeszow. Poland,
}

\begin{abstract}
Eurocod PN-EN 1990 „The basis for structural design” includes general principles for the differentiation of reliability taking into account the consequences of failure. Constructions are classified into three reliability classes RC1 to RC3, for which target reliability indicators have been defined. For the RC2 reliability class the basic values of partial coefficients in relation to materials and loads for persistent and transient computational situations were given. However, Eurocod PN-EN 1992-1-1, „Design concrete structures", proposes to reduce partial coefficients by including quality control of production and available information on the heterogeneity of the materials used. The evaluation of standard recommendations regarding material partial coefficients was made on the basis of analysis of the reinforced concrete bending beam. The standard recommendations provide different levels of reliability. Elements designed in accordance with EN 1992-1-1 to reduce the value of partial factors with tighter quality control and reliability of reinforced concrete elements at RC2 reliability level may not be sufficient for load factors more than 0. 4.
\end{abstract}

\section{Differentiation of reliability according to Eurocode recommendations}

Procedures and measures of reliability management are formulated to enable as differentiation of the reliability of structures and elements. In appendix B to PN-EN 1990 [1] the recommended minimum (target) values of the reliability index $\beta_{d}$ are given. These values of index are for ULS of structures with different reliability classes and for reference periods $T_{0}=1$ year and 50 years (Table 1).

Table 1. Recommended minimum values of the reliability index

\begin{tabular}{|c|c|c|}
\hline $\begin{array}{c}\text { Reliability } \\
\text { class }\end{array}$ & $\beta_{d} / P_{f d} ; T_{0}=1$ year & $\beta_{d} / P_{f d} ; T_{0}=50$ year \\
\hline $\mathrm{RC} 3$ & $5.2 / 9.96 \mathrm{E}-08$ & $4.3 / 8.54 \mathrm{E}-06$ \\
\hline $\mathrm{RC} 2$ & $4.7 / 1.30 \mathrm{E}-06$ & $3.8 / 7.23 \mathrm{E}-05$ \\
\hline $\mathrm{RC} 1$ & $4.2 / 1.33 \mathrm{E}-05$ & $3.3 / 4.83 \mathrm{E}-04$ \\
\hline
\end{tabular}

For other reference periods, the target reliability index values can be calculated using the formula:

$$
\beta_{\mathrm{d}}\left(T_{0}=n\right)=\left\{\Phi\left[\beta_{\mathrm{d}}\left(T_{0}=1\right)\right]\right\}^{\mathrm{n}}
$$

Design calculations using partial factors based on PNEN 1992-1-1 [2] and annexes PN-EN 1990 [1] lead to a construction with RC2 reliability class. This rule can be found in point 2.1.2 of the Eurocod PN-EN 1992-1-1 [2]. Point 2.1.2 [2] regarding reliability management. The standard [2] stated, however, no further recommendations for other classes to obtain reliability. The standard contains only links to the recommendations contained in Annex B and C PN-EN 1990 [1]. Information on other reliability classes is included in PN-EN 1990 [1]

It should be emphasized that the limit state method adopted in the Eurocodes is an example of the level I method. Designing with Level I methods involves the use of a suitable calculation means. This measure allows to achieve an adequate level of structural reliability. his measure is an appropriate set of partial factors related to the uncertainty regarding $[3,5,8,10,12]$ :

- properties of construction materials $\gamma_{m}$,

- the model of load capacity $\gamma_{R d}$,

- representative values of load $\gamma_{f}$

- the model of impacts and effects of load $\gamma_{S d}$.

These coefficients are often combined with the appropriate model uncertainty factors: $\gamma_{M}=\gamma_{m} \gamma_{R d}$ and $\gamma_{F}=\gamma_{f} \gamma_{S d}$.

\section{Correction of the value of partial coefficients}

According to PN-EN 1992-1-1 [2] a set of partial coefficients for concrete and steel $\gamma_{C}=1.4$ and $\gamma_{S}=1.15$ for persistent and transient design situations ensures obtaining RC2 reliability class for construction, except for accident situations. For design accident situations, it

* Corresponding author: izas@prz.edu.pl 
is recommended to use $\gamma_{C}=1.2$ and $\gamma_{S}=1.0$. In other situations it is permissible to use lower values of partial coefficients for concrete and steel, if it is justified by means of reducing the uncertainty in the calculation of the bearing capacity of the structure. These measures are based on the control of the crosssection geometry and quality control of the concrete. Table 2 summarizes the recommendations for reducing the value of partial factors contained in attachment A of PN-EN 1992-1-1 [2].

Table 2. Recommendations for the reduction of a partial material coefficient based on geometry control and concrete strength control in accordance with appendix A [2]

\begin{tabular}{|c|c|c|}
\hline $\begin{array}{l}\text { Reduction } \\
\text { based on } \\
\text { quality } \\
\text { control and } \\
\text { reduced } \\
\text { deviations, } \\
\gamma_{\mathrm{S} \text { red } 1} \\
\text { Reduction } \\
\text { based on } \\
\text { quality } \\
\text { control and } \\
\text { reduced } \\
\text { deviations, } \\
\gamma_{C} \text { red1 }\end{array}$ & $\gamma_{\mathrm{S} \text { red } 1}=1.1$ & $\begin{array}{l}\text { The execution must be } \\
\text { subject to a quality control } \\
\text { system that will ensure } \\
\text { reduction of unfavorable } \\
\text { deviations of cross-section } \\
\text { dimensions } \\
\text { The coefficient of } \\
\text { variation in concrete } \\
\text { strength does not exceed } \\
10 \%\end{array}$ \\
\hline $\begin{array}{l}\text { Reduction } \\
\text { based on the } \\
\text { use of } \\
\text { reduced or } \\
\text { measured } \\
\text { geometric } \\
\text { data in the } \\
\text { project, } \\
\gamma_{\mathrm{S} \text { red2. }} \gamma_{\mathrm{C} \text { red2 }}\end{array}$ & $\begin{array}{l}\gamma_{\mathrm{S} \text { red} 2}=1.05 \\
\gamma_{\mathrm{C} \text { red} 2}=1.45\end{array}$ & $\begin{array}{l}\text { Calculation of the load } \\
\text { capacity of the structure } \\
\text { based on geometrical data. } \\
\text { including the effective } \\
\text { height. which are either: } \\
\text { reduced by deviations or } \\
\text { measured in a finished } \\
\text { structure. }\end{array}$ \\
\hline $\begin{array}{l}\text { Reduction } \\
\text { based on } \\
\text { quality } \\
\text { control and } \\
\text { reduced } \\
\text { deviations, } \\
\gamma_{\text {C red3 }}\end{array}$ & $\begin{array}{l}\gamma_{\mathrm{S} \text { red3 } 3}=1.05 \\
\gamma_{\mathrm{C} \text { red3 }}=1.35\end{array}$ & $\begin{array}{l}\text { Recommended values } \\
\text { maintained. } \\
\text { The coefficient of } \\
\text { variation in concrete } \\
\text { strength does not exceed } \\
10 \% \text {. }\end{array}$ \\
\hline $\begin{array}{l}\text { Reduction } \\
\text { based on } \\
\text { assessing the } \\
\text { strength of } \\
\text { concrete in a } \\
\text { ready } \\
\text { structure, } \\
\gamma_{C} \text { red } 4\end{array}$ & $\begin{array}{l}\gamma_{\mathrm{S} \mathrm{red} 3}=1.05 \\
\gamma_{\mathrm{C} \text { red4 }}=1.3\end{array}$ & $\begin{array}{l}\text { Recommended values } \\
\text { maintained. } \\
\text { Recommended values } \\
\text { maintained. } \\
\text { In the case of concrete } \\
\text { strength values based on } \\
\text { tests in the finished } \\
\text { structure or element. } \\
\text { according to PN-EN } \\
13791 \text {, PN-EN } 206 \text { and } \\
\text { appropriate product } \\
\text { standards. the value of } \gamma_{C} \\
\text { can be reduced by } \\
\text { multiplying by the } \\
\text { conversion factor } \eta= \\
0.85 \text {. The value of } \gamma_{C} \text { to } \\
\text { which this reduction } \\
\text { applies. However. the } \\
\text { resulting value } \\
\text { it can not be smaller than }\end{array}$ \\
\hline
\end{tabular}

\begin{tabular}{|c|c|c|}
\hline & & $\gamma_{\text {Cred4 } 4}$ \\
\hline $\begin{array}{l}\text { Partial } \\
\text { coefficients } \\
\text { for } \\
\text { prefabricated } \\
\text { materials and } \\
\text { elements } \gamma_{\mathrm{S}} \\
\text { pcred. } \gamma_{\mathrm{C} \text { pcred }}\end{array}$ & - & $\begin{array}{l}\text { Reduced partial material } \\
\text { coefficients can be used if } \\
\text { this is confirmed by } \\
\text { appropriate control } \\
\text { methods. level of } 2+ \\
\text { attestation and appropriate } \\
\text { recommendations are } \\
\text { defined in the product } \\
\text { standards. }\end{array}$ \\
\hline
\end{tabular}

Differentiation of reliability within the semiprobabilistic limit state method can also be obtained by adjusting the partial values of safety coefficients for interactions, eg. by introducing multipliers: $K_{F I}=0.9$ for the RC1 class. $K_{F I}=1.0$ for the RC2 class. $K_{F I}=1.1$ for the RC3 class [1].

\section{Quality control and partial material coefficients}

The basic values of partial coefficients in PN-EN 1992 1-1 [2] according to CEN / TC250 guidelines [3] were determined according to the following relationship:

$$
\begin{aligned}
& \gamma_{M}=\exp \left(\alpha_{R} \beta v_{R}-1.64 v_{f}\right) \\
& v_{R}=\sqrt{v_{m}{ }^{2}+v_{G}{ }^{2}+v_{f}^{2}}
\end{aligned}
$$

where: $v_{R}$ - coefficient of variation for bearing capacity. $v_{m}$ - coefficient of variation of uncertainty of the model. $v_{G}$ - coefficient of variation of geometric dimensions and $v_{f}$ - coefficient of variation of material strength and $v_{R}$ sensitivity coefficient for load capacity and $\beta$ - target reliability index

Typical variations for steel and concrete based on Eurocodes and recommended by CEN / TC250 Structural Eurocodes [3] are presented in Table 3. Recommendations describing the variability of steel and concrete under strict quality control were derived in accordance with attachment A to PN-EN 1992-1 -1 [2] (Table 2). It should be noted that the coefficients of variation of strength of material for steel do not change with the improvement of quality control. It is believed that steel production is already well stabilized and is therefore regarded as constant and independent of quality control levels.

Table 3. Typical coefficients of variation for steel and concrete in accordance with [2] and [3]

\begin{tabular}{|c|c|c|c|c|c|}
\hline Material & $\begin{array}{l}\text { Level } \\
\text { of control }\end{array}$ & $v_{m}$ & $v_{G}$ & $v_{f}$ & $v_{R}$ \\
\hline \multirow{2}{*}{ Concrete } & normal & $5 \%$ & $5 \%$ & $15 \%$ & $16.58 \%$ \\
\cline { 2 - 6 } & exacerbate & $45 \%$ & $2.5 \%$ & $10 \%$ & $11.06 \%$ \\
\hline \multirow{2}{*}{ Steel } & normal & $2.5 \%$ & $5 \%$ & $4 \%$ & $6.87 \%$ \\
\cline { 2 - 6 } & exacerbate & $1.5 \%$ & $2.5 \%$ & $4 \%$ & $4.95 \%$ \\
\hline
\end{tabular}

Figure 1 presents charts drawn up on the basis of equation (2) for two cases of normal quality control (NQC) and exacerbate quality control (IQC). They are according to the recommended values of coefficients of 
variation (Table 3), indicating the influence of partial coefficients for concrete $\left(\gamma_{C}\right)$ and for steel $\left(\gamma_{S}\right)$, on the value of the target reliability index. According to PN-EN 1990 [1] and PN-EN 1992-1-1 [2] for normal quality control and adopted partial coefficients: $\gamma_{C}=1.4$ for concrete and $\gamma_{S}=1.15$ for steel. the construction belongs to the RC2 reliability class (Fig 1).

The distinction between $\mathrm{RC} 1, \mathrm{RC} 2$ and $\mathrm{RC} 3$ reliability classes set by the PN-EN 1990 standard [1] is taken as the key in describing the impact of quality control on the value of partial coefficients. For example, the transition from RC2 to RC3 means an increase in the target reliability of the structure from 3.8 to 4.3 for a 50 year reference period. This has practical consequences resulting from the different levels of quality related to project supervision and inspection of construction works. Proper implementation of these measures can be effective in achieving the appropriate level of control required to control geometric dimensions and concrete strength, which guarantees partial reduction of the coefficient. This rule can be found in annex A to PN-EN 1992-1-1 [2].

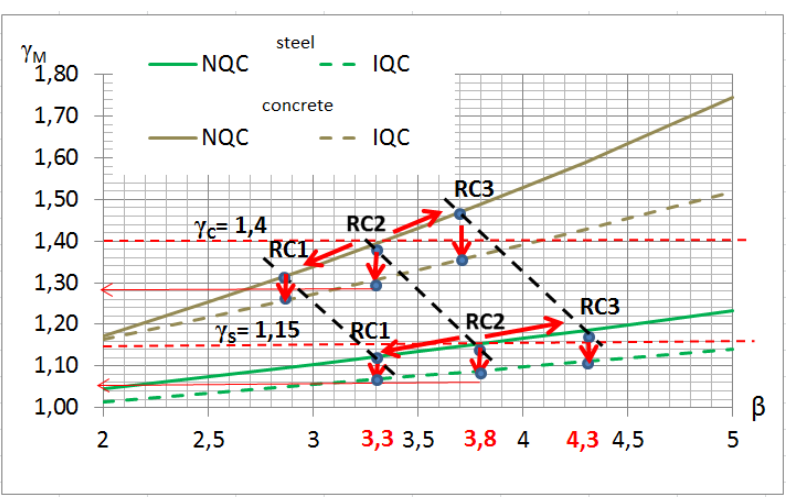

Fig. 1. Material partial coefficients correlated with quality control (NQC - normal quality control and IQC - tightened quality control) for reliability classes RC2 and RC3

If the decision is made to improve the quality control measures, the modified partial factors should be corrected upwards for the RC3 class structure or downwards for the $\mathrm{RC} 1$ class structure. This is shown in Figure 1. In PN-EN 1990 [1] only the general principles of reliability differentiation are given taking into account the consequences of failure, while in PN-EN 1992-1-1 [2] there are no clear guidelines on how to adjust the partial coefficients for the RC3 or RC1 reliability class.

The increase in the level of control and reduction of coefficients of variation for individual materials, together with the implementation of quality control measures and the assignment of appropriate reliability classes to them, as shown in Figure 1, should indicate the effectiveness of quality control measures in the required reduced partial factor for concrete $\left(\gamma_{C}\right)$ and for steel $\left(\gamma_{S}\right)$. However, this correction in accordance with the recommendations contained in PN-EN 1992-1-1 is only a compensation measure aimed at maintaining the level of reliability.

It is proposed:

$\checkmark$ target reliability levels for reliability classes. RC1. RC2 and RC3 according to PN-EN 1990 [1], and $\checkmark$ corrected values of material partial factors for better quality control. as suggested by PN-EN 1992-1-1 [2].

These are two alternative methods for managing the reliability of a structure. A higher level of quality control enables us differentiation of the reliability of the structure and is an effective method in reliability management. The $\gamma_{C}(1.37)$ values for concrete and $\gamma_{S}$ (1.09) for steels (obtained according to formula (2) and table 3) obtained for better quality control can be compared with the values 1.35 and 1.05 indicated in table 2, as shown by of attachment A in PN-EN 1992-11 [2] (Fig. 1). The use of smaller values of partial coefficients recommended according to PN-EN 1992-1-1 [2] indicates the inclusion of higher level / better quality control. The more difficult issue is the adaptation of PNEN 1992-1-1 [2] procedures for RC2 in relation to other reliability classes, in particular for RC3 class construction.

\section{Verification of recommended partial coefficients}

The properties and quality of materials have an effect on the assessment of the reliability of building structures. The influence of material partial coefficients on concrete and steel on the level of reliability was evaluated on the basis of analyses carried out for the reinforced concrete bending beam, taking into account the level of material quality control and the recommended partial material factors. This effect for reinforced concrete constructions designed according to PN-EN 1992-1-1 [2] was determined by calculate the reliability index. This study limits the considerations to the recommended by the standards PN-EN 1990 [1] and PN-ISO 2394 [4] reliability index methods $\beta$, using the First Order Reliability Method (FORM).

In typical cases. the safety condition regarding the limit state of a structural element can be described as (4):

$$
R_{\mathrm{d}} \geq E_{\mathrm{d}}
$$

where: $E_{\mathrm{d}}$ is the design value of the load effects. and $R_{\mathrm{d}}$ is the designed bearing capacity of the structural element in relation to the $E$ loads.

Loads can be classified based on a number of different criteria. For example: including due to the variability in time: dead and variable, variability in space: free and non-free, the type of the impact on the structure: static, dynamic, and due to the reason for the uprising: caused by natural phenomena: snow, wind, caused by human activity (technological load), whether subject to control and disasters. Analysis of the structural element / structure must take into account the influence of all loads that can have a significant impact on the structure $[1,20]$.

In the work with regard to the analysed structural element only dead loads and one variable load are considered.

PN-EN 1990 [1] defines the characteristic values of dead loads as 95\% quantiles when the effects are unfavorable or when the effects are favorable. The 
probabilistic model for dead loads is usually a normal distribution [6, 9, 11-24].

The accepted variable load in the conducted analyses is the variable load in buildings, commonly represented by log-normal distributions [6, 9, 11-24]. Alternatively. stochastic models [23] are used. describing the temporal variability of these interactions (not included in this work).

Dead loads and variable loads in accordance with PN-EN 1990 [1] are connected by the following relationship (5):

$$
E_{d}=G_{k} \cdot \gamma_{g} \cdot \xi+Q_{k} \cdot \psi_{0.1} \cdot \gamma_{q}
$$

where: $E_{d}$ - design effect of loads.

$G_{k}$ - characteristic value of the dead load effect.

$Q_{k}$ - characteristic value of the variable load effect.

Values of partial coefficients for loads contained in equation (4). according to PN-EN 1990 [1], are $\gamma_{g}=$ $1.35, \xi=0.85, \gamma_{q}=1.5, \psi_{0.1}=0.7$.

In the case of linear structure analysis (first order effects), where the superposition principle can be applied. the effects of loads can be combined with partial factors according to (5).

The designed bearing capacity of a structural element is determined by the adopted calculation model and material properties. Characteristic values $\left(f_{k}\right)$ of material or product properties are values corresponding to the assumed probability of not exceeding them in a theoretically unlimited series of tests. Usually. they correspond to the specified quantile of the adopted statistical distribution of a specific material or product property. Assuming a normal distribution. the characteristic value can be determined using the dependence (6):

$$
f_{\mathrm{k}}=f_{\mathrm{m}}-1.645 \sigma=f_{\mathrm{m}}(1-1.645 \mathrm{v})
$$

where: $f_{\mathrm{m}}$ - medium strength of material;

$\sigma / \mathrm{v}$ - standard deviation / material strength variation coefficient.

The statistical model of compressive concrete strength was adopted on the basis of the models proposed in [6], [9], [11-24]. The log-normal distribution was used to describe the distribution of the probability of concrete compressive strength. The coefficient of variation of concrete was assumed as 0.15 for normal quality control and 0.10 for tight quality control. in accordance with Table 1 developed on the basis of [2].

For the description of the steel strength probability distribution, according to [6], [9], [11-24], log-normal distribution was also used. The coefficient of variation for tensile strength of steel was adopted in accordance with [6], [9], [11-24] at the level of 0.04 .

\section{Example}

In order to determine the impact of quality control and the recommended standard partial coefficients on the value of the reliability index in structural reinforced concrete elements, calculations were made by probabilistic methods for the reinforced concrete beam. The reliability index values obtained were compared with the recommended values of the reliability index for individual reliability classes and the reference period of 50 years recommended in PN-EN 1990 [1].

The analysis includes a reinforced concrete bending beam with material parameters: BS500 steel. C25/30 concrete and geometrical dimensions: $b=40 \mathrm{~cm}, h=60$ $\mathrm{cm}$.

The reinforcement diameter : $\phi 20 \mathrm{~mm}$. stirrups : $\phi 6 \mathrm{~mm}$ :

$c_{\text {nom }}=c_{\text {min }}+\Delta c_{\text {dev }}, c_{\text {min }}=\max (20.10 .10)=20 \mathrm{~mm}$ for main bars.

$c_{\text {nom }}=c_{\text {min }}+\Delta c_{d e v}, \quad c_{\text {min }}=\max (6.10 .10)=10 \mathrm{~mm}$ for stirrups

$\Delta c_{\text {dev }}=10 \mathrm{~mm}$, recommended value by the national appendix

$c_{\text {nom }}=30 \mathrm{~mm}$ lub $c_{\text {nom }}=20 \mathrm{~mm}$

$C_{\text {nom }}$ due to fire resistance REI60: $a=25 \mathrm{~mm}$ - distance to the element axis.

The usable depth of the section is:

$d=\min \left(h-c_{\text {nom }}-0.5 \phi, h-a\right)=\min (600-30-0.5 \cdot 20,600$ 25) $=560 \mathrm{~mm}$

The limit state is defined as follows (7):

$$
Z=\theta_{R}\left[A_{s} \cdot f_{y} \cdot(d-a)-0.5\left(A_{s}{ }^{2} \cdot f_{y}^{2}\right) /\left(b \cdot f_{c}\right)\right]
$$$$
\text { - } \theta_{E} \cdot\left(M_{G}+M_{Q}\right)
$$

$\theta_{R} . \theta_{E}$ - uncertainty of the calculation model for load resistance and load effect.

Density functions and distribution parameters for random variables to perform calculations by means of probabilistic methods are presented in Table 4 and 5.

The coefficients of variation for particular variables were adopted in accordance with publications [6, 9, 11-24]. These data were obtained from several sources $[6,9,13$, $18,20,21,24]$ and were compared with the national literature $[7,8,10,12,19,22-23]$.

\begin{tabular}{|c|c|c|c|c|c|}
\hline \multirow[b]{2}{*}{ 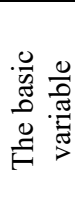 } & \multirow[b]{2}{*}{ 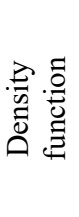 } & \multirow[b]{2}{*}{ 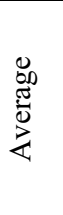 } & \multicolumn{2}{|c|}{ Material factors } & \multirow[b]{2}{*}{$\stackrel{\Xi}{\Xi}$} \\
\hline & & & $\begin{array}{c}\text { Normal } \\
\text { Quality } \\
\text { Control } \\
\gamma_{C}=1.43 \\
\gamma_{S}=1.15\end{array}$ & $\begin{array}{c}\text { Exacerbated } \\
\text { Quality } \\
\text { Control } \\
\gamma_{C}=1.3 \\
\gamma_{S}=1.05\end{array}$ & \\
\hline$f_{y}$ & $\mathrm{LN}$ & 535 & 0.04 & 0.04 & $\mathrm{MPa}$ \\
\hline$f_{c}$ & $\mathrm{LN}$ & 33 & 0.15 & 0.10 & $\mathrm{MPa}$ \\
\hline$h$ & $\mathrm{~N}$ & 0.6 & 0.03 & 0.015 & $\mathrm{~m}$ \\
\hline$a$ & $\mathrm{~N}$ & 0.04 & 0.002 & 0.001 & $\mathrm{~m}$ \\
\hline$b$ & $\mathrm{~N}$ & 0.4 & 0.02 & 0.01 & $\mathrm{~m}$ \\
\hline
\end{tabular}

Table 4. The basic variables depend on the properties of materials, their density functions and distribution parameters 
Table 5. The basic variables independent of the properties of materials, their density functions and distribution parameters

\begin{tabular}{|c|c|c|c|c|}
\hline 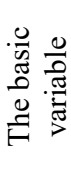 & 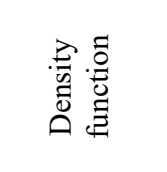 & 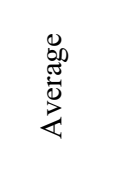 & 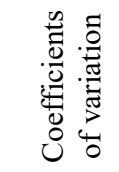 & 氙 \\
\hline$A_{s}$ & $\mathrm{~N}$ & $134.5 e-5$ & $67.25 e-5$ & $\mathrm{~m}^{2}$ \\
\hline$G$ & $\mathrm{~N}$ & $\mathrm{G}_{\mathrm{m}}$ & 0.05 & $\mathrm{kN} / \mathrm{m}^{2}$ \\
\hline$Q$ & G (Gumbel) & $\mathrm{Q}_{\mathrm{m}}$ & 0.2 & $\mathrm{kN} / \mathrm{m}^{2}$ \\
\hline$\theta_{R}$ & LN & 1 & 0.1 & - \\
\hline$\theta_{E}$ & $\mathrm{LN}$ & 1 & 0.1 & - \\
\hline
\end{tabular}

The calculations assume that all random variables are uncorrelated variables.

The procedure for reliability analysis, in relation to the level of quality control and partial coefficients recommended in PN-EN 1990 [1] and PN-EN 1992-1-1 [2], can be presented in accordance with the following algorithm:

- Calculate the design load resistance of a reinforced concrete element: $R_{d}$,

- Accept that the design load capacity of a bending reinforced concrete element is equal to the designed effect of load: $R_{d}=E_{d}$,

- Transform the effect of load into the characteristic values for the effect of constant and variable load according to the relationship (8), (9):

$$
\begin{aligned}
& G_{k}=E_{d} /\left[\gamma_{g}+\gamma_{q} \cdot \chi /(1-\chi)\right] \\
& Q_{k}=E_{d} /\left[\gamma_{g} \cdot(1-\chi) /\left(1+\gamma_{q}\right)\right]
\end{aligned}
$$

- Define the retio between dead and live load according to the formula (10):

$$
\chi=Q_{k} /\left(G_{k}+Q_{k}\right)
$$

- Re-determination of statistical parameters (mean and coefficient of variation) for random variables depending on the properties of materials and geometrical features,

- Estimation of the probability of exceeding the ultimate limit states and the corresponding reliability indexes for individual ratio belonging to the range $\chi \in(0 ; 1.0)$.

On the basis of the analyses carried out (Figures 2 and 3), a significant influence of the quality of materials and recommended standard partial material factors on the received values of the reliability index of a bending reinforced concrete element was noticed. The reliability of the beam assuming the basic quality of production is shown in Figure 2, while for the tightened quality control in Figure 3.

Based on calculations using the analytical method FORM for the analyzed bending beam made of concrete class C30/37 and steel BS500, assuming that the compressive strength and strength of steel are stochastically independent variables and ensure normal / basic quality control / material production and partial coefficients $\gamma_{C}=1.4$ and $\gamma_{S}=1.15$, it was found that for the reference period of 50 years the requirements for the reliability class RC 2 for the ratio $\chi$ from 0.1 to 0.6 are met. On the other hand, based on calculations of a higher level - simulated by the Monte Carlo method, the received values of the reliability index meet the requirements for all reliability classes regardless of the value of the load factor (Figure 2).

According to the recommendations of PN-EN 1990 [1] and the adopted partial factors for loads and materials, the worst case scenario is the situation in which the variable load $\left(Q_{k}\right)$ is relatively large in relation to the dead load $\left(G_{k}\right)$, then the value of the reliability index is greater than the recommended target value of the reliability index for the $\mathrm{RC} 2$ class $(\beta=3.8)$. When the parameter value $\chi$ is small, then the permanent load is a decisive variable influencing the value of the reliability index and when $\chi$ is large, then the variable load becomes the determining variable. For the ratio $\chi=0.7$, the value of the reliability index obtained using iterative procedure is 3.75 , while the values obtained by the Monte Carlo simulation method (MCM) meet the requirements of the permissible value of the reliability indicator for the $\mathrm{RC} 2$ cash register.

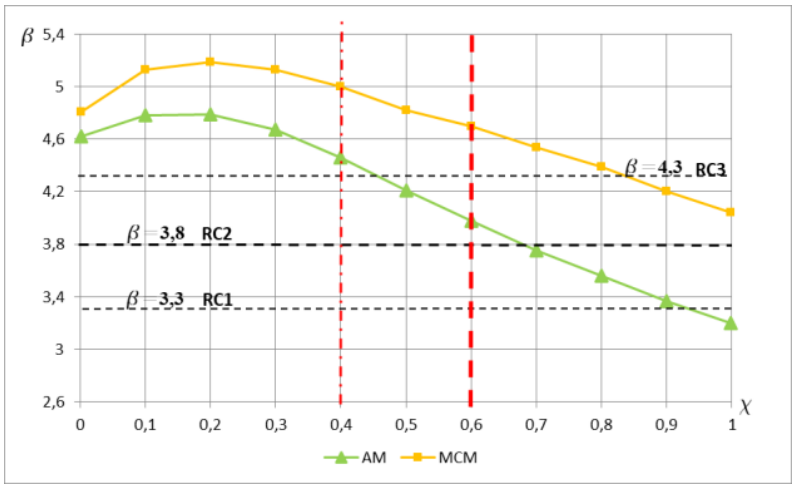

Fig. 2. Reliability index for normal quality control by order PN-EN 1990 [1]

The reliability analysis carried out for the recommendations contained in PN-EN 1992-1-1 [2] indicates the effect of tightened quality control and reduced partial material factors $\gamma_{C}=1.3$ and $\gamma_{S}=1.05$ on the obtained values of reliability index $\beta$ (Figure 3 ) irrespective of the calculation method used.

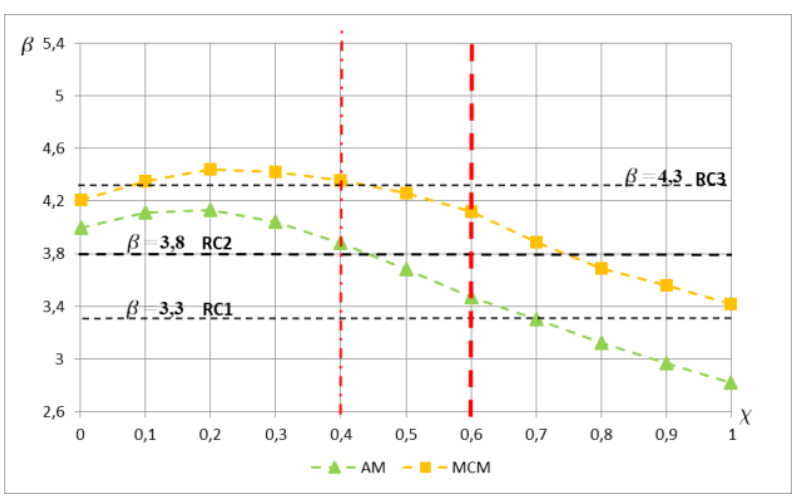

Fig. 3. Reliability index for tight quality control in accordance with PN-EN 1992 [2] and PN-EN 1990 orders

For ratio $\chi$ greater than 0.6 , the reliability ratios obtained significantly decrease and are smaller than the target value of the reliability index for the RC2 class. Sufficient 
reliability for the $\mathrm{RC} 2$ reliability class for the analysed reinforced concrete beam with the analytical method FORM was found for ratio up to $\chi=0.43$. On the other hand, based on the Monte Carlo simulation (MCM) calculation and the load factor from the range $(0,0.7)$, the obtained values of the reliability index meet the requirements for the $\mathrm{RC} 2$ reliability class (Fig. 3,4,5).

The graph of dependence of the reliability index value as a function of the load index calculated for various standard recommendations according to PN-EN 1992 [2] and PN-EN 1990 using the analytical (AM) and Monte Carlo (MCM) simulation methods is shown in Figures 4 and 5.

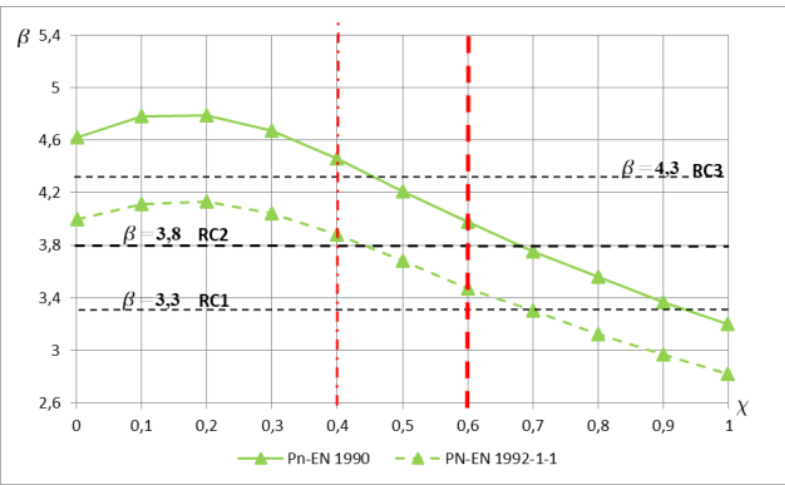

Fig. 4. Reliability index as a function of the load ratio calculated for the standard recommendations according to PNEN 1992 [2] and PN-EN 1990 using the analytical method (AM)

Probabilistic analysis shows (Figures 4, 5) that the application of reduced values of partial coefficients for the properties of materials proposed in PN-EN 1992-1-1 [2] may in some cases, for load ratio $\chi>0.4$, lead to insufficient level of reliability.

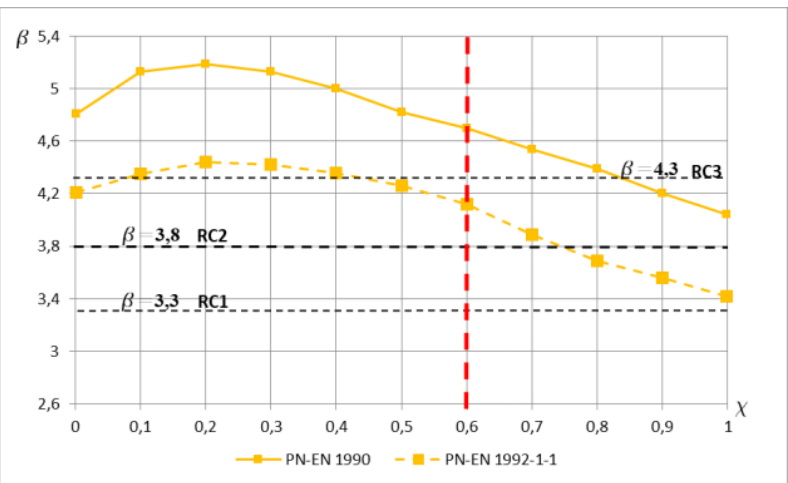

Fig. 5. Reliability index as a function of the load ratio calculated for the standard recommendations according to PNEN 1992 [2] and PN-EN 1990 using the Monte Carlo simulation method (MCM).

\section{Conclusion}

The probabilistic analysis concerning the reliability of the reinforced concrete bending beam made of concrete class $C 30 / 37$ and steel $B S 500$ regarding the recommendations contained in PN-EN 1990 and PN_EN 1992-1-1 in relation to partial factors for loads and materials and coefficients of variability of material properties leads to the following conclusions:

$\checkmark$ On the basis of calculations performed using the semi-probabilistic method, it was found that the reduced partial coefficients recommended in EN 1992-1-1 for strength of concrete and reinforcing steel in the case of higher production quality for load ratio $\chi>0.4$ are lower than the recommended value of reliability index $\beta=3.8$ for RC2 designed with basic (not reduced) partial coefficients. Lowering the value of coefficients is a deliberate procedure, but definitely requiring further analysis.

$\checkmark$ The standard does not provide detailed recommendations on the use of other reliability classes than $\mathrm{RC} 2$ with respect to the material quality level.

\section{References}

1. EN 1990:2002 Eurocode - Basis of structural design. 2002 CEN.

2. PN-EN 1992-1-1: 2008 Eurocode 2 - Design concrete structures - Part 1-1: General rules and rules for buildings

3. CEN/TC250 - Structural Eurocodes, https://standards.cen.eu/dyn/www/f?p=CENWEB:1 05::RESET::::\#top

4. PN-ISO 2394: General principles of reliability of building structures, 2010

5. Probabilistic Model Code (JCSS), 2001

6. M. Bournonville, J. Dahnke, D. Darwin, 2004, "Statistical Analysis of the Mechanical Properties and Weight of Reinforcing Bars," SL 04-1, University of Kansas, Lawrence

7. L. Czarnecki and others, Concrete according to PNEN 206-1 Commentary, Polish Cement, 2007

8. Ł. Drobiec, R. Jasiński., A. Piekarczyk, Masonry structures according to Eurocode 6 and related standards, vol. 2, chapter Fundamentals of Designing Structures, PWN, Warsaw, 2013

9. M.H. Faber, J.D Sorensen, Reliability Based Code Calibration, JCSS, Paper for the Joint Committee of Structural Safety, March 2002, p. 3-17

10. M. Giżejowski, Z. Stachura, Partial coefficients in the assessment of the load-bearing capacity of a cross-section element of steel structures, Construction and Architecture, 12 (2), 213-220 (2013)

11. H. Gulvanessian, M. Holicky, Eurocodes: Using reliability analysis to combine action effects, Proceedings of the Institution of Civil Engineers, Structures and Buildings, Thomas Telford, August 2005, pp. 243-252

12. M. Gwóźdź, A. Machowski, Selected research and calculation of building structures using probabilistic methods, Cracow University of Technology, 2012 
13. M. Holicky, J. Markova, Verification of load factors for concrete components by reliability and optimization analysis: Background documents fot implementing Eurocodes, Progress in Structural Engineering and Materials, 2 (4), 502-507 (2000)

14. M. Holicky, J.V. Retief, Reliability assesssment of alternative Eurocode and South African load combination schemes fot structural design, Journal of and South African Institution of Civil Engeenering, 47 (1), 15-20 (2005)

15. M. Holicky, D. Diamantidis, M. Sykora, Effect of quality control on reliability of reinforced concrete structures according to eurocodes, from: https://www.researchgate.net/publication/31061667 6_Effects_of_quality_control_on_reliability_of_rein forced_concrete_structures_according_to_Eurocode s [accessed Mar 15 2018].

16. M. Holicky, Reliability analysis for structural design, Sun Press (2009)

17. K.K. Mensah, Reliability assessment of structural concreto with special reference to stirrup design, , $\mathrm{PhD}$, Philosophy in civil Engeenering at Stellenbosch University

18. A. Nowak, K. Collins, Reliability of Structures, 2012, CRC Press
19. J. Pawlikowski, Probabilistic analysis of the standard safety stock accepted for consideration of dead and variable loads, ITB, 112 (4), 3-16 (1999)

20. D.M. Santos, D.M. Stucchi, A.T. Beck, Reliability of beams designed in accordance with Brazilian codes, On-line version ISSN 1983-4195,

21. Rev. IBRACON Estrut. Mater. vol.7 no.5 São Paulo Sept./Oct. 2014http://dx.doi.org/10.1590/S198 3-41952014000500002

22. J.D. Sorensen, S.O Hansen, T.A. Nielsen, Partial Safety Fators and Target reliability level in Danish Codes, Proc.: Safety, Risk, and reliability, IABSE, Malta, 2001, pp. 179-184

23. Sz. Woliński, K. Wróbel, Reliability of building structures, Rzeszow, in Polish (2001)

24. Sz. Woliński, Fundamentals of Designing Structures in General Construction, ed. Lichołai Lech, PWN t 3, pp. 112-146, in Polish (2003)

25. https://www.researchgate.net/publication/29113954 6_ReliabilityBased_Study_on_Ductility_Measures of Reinforced Concrete Beams in ACI 318 